\title{
Research on MOOC Learning Effectiveness
}

\author{
Yong Luo ${ }^{1,2}$ \\ ${ }^{1}$ College of Science \\ National University of Defense Technology \\ ${ }^{2}$ Hunan Provincial Key Laboratory of Network \\ Investigational Technology \\ Changsha, China
}

\author{
Jianping Li \\ College of Science \\ National University of Defense Technology \\ Changsha, China
}

\author{
Guochang Zhou \\ College of Science \\ National University of Defense Technology \\ Changsha, China
}

\author{
Xiao Xiao \\ Higher Education Press, \\ Beijing, China
}

\begin{abstract}
The rapid development of MOOC, and more and more people learn online by it. However, MOOC faces the problem of very high dropout rates, and lack of curriculum evaluation system. The traditional pass rate assessment model is clearly unreasonable. This article researched the effectiveness of learning behaviors. Based on the theory of effective learning, MOOC learners are divided into three categories. They are authenticator, observer and visitors. The pass rate for each type of learner is completely different. Their core distinctions are based on effective le arning. So it can reasonably classify learners' behaviors and provide new ideas for course evaluation. At the same time, it can also provide reference for different learners to design corresponding le arning solutions.
\end{abstract}

Keywords-MOOC; Course evaluation; learning effectiveness

\section{INTRODUCTION}

MOOC is the large open online courses. These courses are provided by internationally renowned university, and shared through the network. It enables global sharing of quality course. Coursera, Udacity, edX are currently the three largest providers in the world. MOOC is also developing rapidly in China. NetEase and iCourse Network launched a "China University MOOC" project in May 2014.

Its philosophy is to enable global learners to share quality resources through information technology and web technologies[1]. MOOC have a complete set of teaching modes. Including registration, watching video lectures, quizzes, assignments, discussions, exams, graduation, certificates and other processes. These teaching models to learners brought a new experience, and give chance to get involved in high education. At the same time, through sharing the resources, the college courses can also be improved.

Although it has been rapid development and recognition, but there are still many controversies. From the history of online education, changes in learning resources promote the revolution in learning styles [2]. How to use online course resources scientifically is a common concern. Another problem is how these courses enter into the university curriculum system. Many schools have started to try MOOC certificates linked to credits. Transplant MOOC resources into the classroom. These new teaching methods and modes open up new areas of university education.

The United States, Britain, Japan and other economically developed countries have accumulated a great deal of experience in practice. In MOOC learning behavior data analysis, Anderson [3] found through data mining technology some of the factors that affect the learning effect of MOOC course. Adamopoulos [4] studied the factors that affect the retention rate of MOOC students. Gillani [5] analyzed "Business Strategy Fundamentals" course 87,000 trainees in the course forums and the relationship with grades. Guo [6] studied the relationship between MOOC video mode and learning effect through data analysis, and proposed a scientific and reasonable course video recording mode. Domestic MOOC teaching and research focused on MOOC in teaching practice and quality control. Jiang [7] classify learners according to the Chinese MOOC learning behavior characteristics. He studied in depth the relationship between learning behavior and outcomes. Deng [8] paid attention to MOOC's problems in quality assurance and evaluation mechanism.

\section{The Classification OF MOOC LEARNERS}

Data show that the most important motivation for MOOC learner comes from obtaining knowledge and ability. The course certificate is more of an honor attribute. Thus, to gain the course certificate is not the main target for them. There are many learners who do not even have the goal of learning. They are attracted to the new teaching mode. Most of the time spent in aimless browsing. 


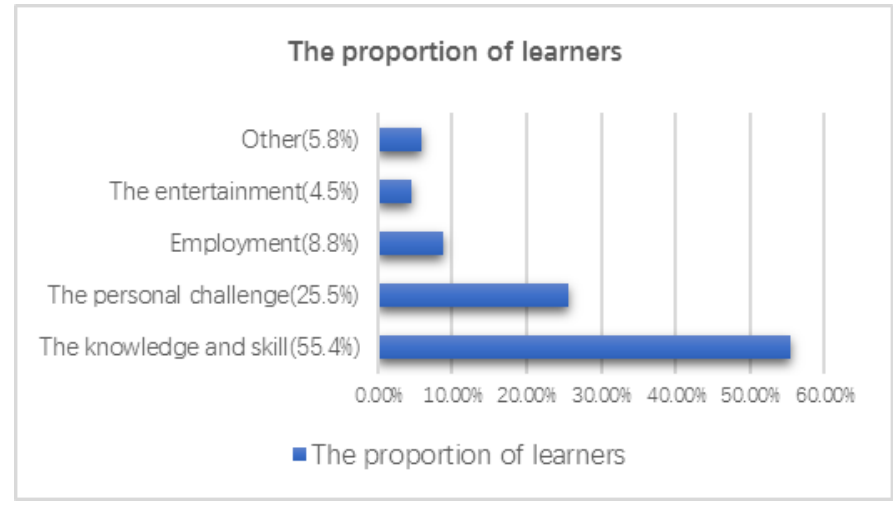

Fig. 1. Learning purpose and its proportion

From the figure above, we can see that more than half of learners (55.4\%) learned for knowledge and skills. Another quarter of people look for challenges for themself. Obviously, we should design scientifically to meet the mainly needs of learners. It is the direction of development.

The first problem learners face is how to choose a course. In many cases, the course does not meet learners' expectations. Or the basic knowledge mastered did not meet the requirements of course learning. Many learners have given up their studies. Of course, there are still many learners to learn the goal is to master a point of knowledge. So, these people will not complete the course study. Only a handful of people completed the course and got the final certificate. We need to distinguish these learners. In this paper, a method of learner classification is proposed.

In this article, MOOC learners are divided into three categories, such as authenticator, observer and visitors. Authenticator is the real MOOC learner. Learning courses have a high interest and motivation. According to the requirements of the course to complete the learning objectives. After analysis, authenticator is divided into two categories. One is an active learner. There is a practical problem in the study and work that needs the knowledge of the course to solve. The other is passive learners. Many universities now require students to register and learn the course in the MOOC platform. These students are not free to choose courses. MOOC courses are part of their training program. They have to complete the whole course to get credits.

This learning model can promote and supplement traditional university education. It is also the main mode of university integration with MOOC. Bring a powerful impact on the traditional classroom education. But on the other hand, purely formal change did not stimulate learners' enthusiasm. On the contrary, due to the imperfect evaluation system, it is easy to cause poor learning quality. Students are perfunctory about classes they are not interested in. Based on this phenomenon, it is very necessary to compare the behaviors of active and passive learners. Through data analysis, define the indicators. Verify that active learners have better learning outcomes than passive ones.

As for observer, they are interested in a part of the course. But there is no long-term learning behavior. The goal of such learners is often to grasp a certain point of knowledge. Enhance their abilities through knowledge acquisition. These learning behaviors are helpful.

As for visitor, learners do not have a clear purpose of learning. They entered the class with a curiosity. The process did not produce effective learning behavior.

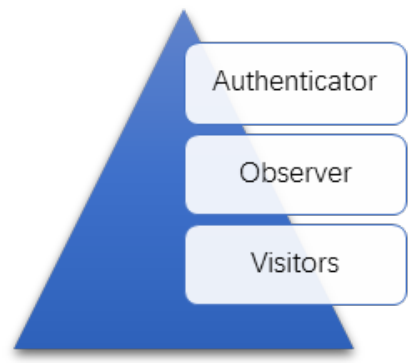

Fig. 2. MOOC learner classification

\section{COMPLETION RATE AND EFFECTIVE LEARNING}

Data show that the most important driving force for student learning is to acquire knowledge and improve ability. At present, many agencies in the world carry out big data analysis on MOOC. Adjust the platform architecture, course content, learning sessions, and video production and so on, to improve the MOOC course completion rate. However, the course completion rate is still low. Here's part of course data on Coursera.

TABLE I. COURSE COMPLETION RATE DAT A

\begin{tabular}{|c|c|c|c|c|}
\hline University & Course title & Enrollment & $\begin{array}{l}\text { Completed } \\
\text { number }\end{array}$ & $\begin{array}{c}\text { Completion } \\
\text { rate }\end{array}$ \\
\hline MIT & $\begin{array}{l}\text { Circuits and } \\
\text { Elect }\end{array}$ & 155000 & 7157 & $4.6 \%$ \\
\hline Michigan & $\begin{array}{c}\text { Internet } \\
\text { technology } \\
\text { and security }\end{array}$ & 45572 & 4595 & $10 \%$ \\
\hline Berkeley & $\begin{array}{c}\text { Software } \\
\text { Engineering }\end{array}$ & 50000 & 3500 & $7 \%$ \\
\hline Google & $\begin{array}{l}\text { Search } \\
\text { engine }\end{array}$ & 155000 & 20000 & $13 \%$ \\
\hline Duke & Bioelectricity & 12725 & 313 & $2.5 \%$ \\
\hline
\end{tabular}

MOOC completion rate basically maintained at between $7 \%-9 \%$. Can be seen, a simple self-organized learning, its efficiency is limited. The social nature of people determines that learning requires external supervision and management. Starting in 2013, I was a tutor for the MOOC course "Introduction to Mathematical Thinking" on the Coursera. Completed five rounds of electives. After statistics found that the average attendance rate at $15.2 \%$. As can be seen from the data, the teacher's supervision can improve the completion rate. However, the passing rate is still far below the classroom teaching. 
TABLE II. CREDITS COURSE COMPLETION RATE DATA

\begin{tabular}{|c|c|c|c|}
\hline Year & Semester & Enrollment & Completed number \\
\hline $\mathbf{2 0 1 3}$ & Fall & 24 & 3 \\
\hline $\mathbf{2 0 1 4}$ & Fall & 60 & 8 \\
\hline $\mathbf{2 0 1 5}$ & Spring & 14 & 2 \\
\hline $\mathbf{2 0 1 6}$ & Spring & 7 & 3 \\
\hline $\mathbf{2 0 1 7}$ & Spring & 30 & 7 \\
\hline
\end{tabular}

Therefore, we should not just use the completion rate to evaluate learning behavior. Effective learning should be used to evaluate behavior. Effective learning is defined as behaviors that acquire knowledge and skills. It should include the following categories.

- Complete all course contents, pass the test, get the certificate;

- Complete all course content, failed the test;

- Learning a single point of knowledge, and complete the practice;

- Continuous browsing the entire knowledge point video;

- Completed the course test, and the result reached a certain standard;

- Forum posts, discussions with teachers or learners to master certain knowledge.

Of course, we could not list all the validated learning behaviors. There are still some behaviors that can achieve the learning effect. And the impact of each learning behavior on the individual is not the same. More in-depth study of learning behaviors and their impact on learners are needed.

\section{MOOC LEARNING MODE}

The main motivation for the MOOC course is demand knowledge. Therefore, the vast majority of learners do not choose a complete course of study. The previous data proves this. How to find the knowledge you want to learn is the need of most learners. Therefore, MOOC should be based on the needs of different learners to provide the appropriate model. We can divide the online learning model into two types: the knowledge model and the curriculum model. Knowledge mode refers to the learner needs to master a certain knowledge point or a certain knowledge module. The system automatically generates the knowledge tree. Includes knowledge points and related knowledge. According to the knowledge tree to learn, you can grasp the knowledge.

Course mode refers to the complete course of study. However, the current curriculum model also has a big problem. Due to the delivery of resources is the semester approach, it is difficult to adapt to the learners' time. Therefore, in the curriculum model, the delivery of resources should be customized. Cancel existing semester system. Learners can start the course at any time. The release of learning resources is based on personal learning habits to be customized. The system intelligently analyzes learning behavior. Optimize your learning plan and improve your learning.

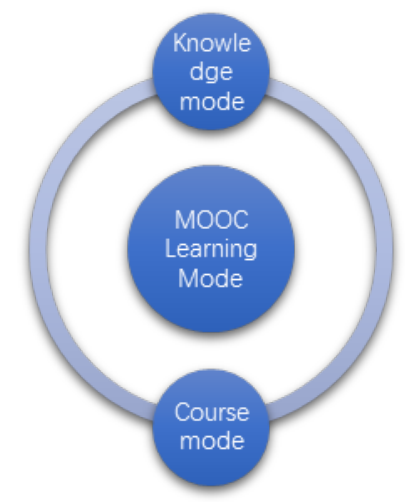

Fig. 3. Course learning mode

Here's an example of a knowledge tree. You can see the system-generated knowledge tree structure. Contains the level of knowledge points and related knowledge.

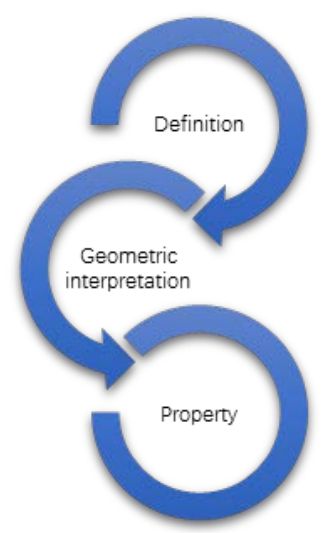

Fig. 4. A knowledge tree instance

Knowledge mode and course mode will be customized. Learners in the learning process can choose the knowledge point resources and auxiliary resources. For course mode, the system formulates push rules for knowledge points and auxiliary resources. For example, each knowledge point must choose a resource to learn. Auxiliary resource requirements are based on the course requirements.

\section{EFFECTIVE LEARNING BEHAVIOR}

\section{A. Getting credits does not equal getting knowledge}

Effective learning refers to the acquisition and mastery of course knowledge. Effective learning can improve one's ability. Many people choose courses they have already studied. Just to get the certificate. Such learning is not effective learning. Effective learning behavior is difficult to distinguish. We often use the course exercises and tests to distinguish. However, some learners only viewed the video without participating in the test. This analysis of learning effectiveness requires learning behavior data. For example, the learner's behavior will reveal their purpose. We think learning without purpose is inefficient. Effective learning often requires spending enough time on one resource. The goal of learning is very clear. Such learning behavior is an effective learning behavior. The number 
of effective learning behaviors can be used as a criterion for evaluating the quality of a course.

\section{B. Effective learning can be assessed level of course.}

In the online world, once there is a profit, there will be an unfair means to undermine the balance. It is clearly unscientific to use the course size and page views to evaluate the level of the course. Some useless accounts, some invalid learning behavior will cover the true level of the course. Unscientific course evaluation can undermine the healthy development of MOOC. Effective learning is an important assessment of the course level. Not all elite schools and famous teachers can set up excellent courses. We need rational thinking and choice to be able to learn effectively.

\section{Effective learning should be the platform and course goal.}

Effective learning assessment methods guide MOOC builders in designing better curricula. Should not be cheating means, the use of some invalid account for higher rating. Attracting learners is to give them more freedom and faster access to knowledge. This will further enhance the learner's dominant position. Really build a course into a course that serves online learners. Really make MOOC serve online learners. Not just the pursuit of popularity.

Letting learners customize content and planning is also a way to increase efficiency. In fact, the certificate of course exists only as honor. In many cases, learners find it hard to get enough motivation to complete the course. But learning without a certificate is also valid. Personalized learning meets the needs of most learners.

\section{Knowledge structure to ensure that learners access quickly and easily}

Existing knowledge organization adopts the mode of classroom teaching. Video segmentation is not enough fine. The level of knowledge points could not be directly obtained. A lot of time spent browsing and finding knowledge points in the process. On the other hand, knowledge learning is relevant. Do not learn the basics, direct learning is very difficult. Therefore, the establishment of knowledge map is the core means to break through the current MOOC bottleneck. The establishment of a knowledge map can improve effective learning. Improve learning efficiency. Truly allow learners to enhance themselves.

\section{SUMMARY}

The origin and development of MOOC comes from the need of knowledge. Higher education institutions share their popular teaching resources. Learners are attracted to the course. However, with the further development of MOOC, many lowquality courses make learners feel lost. By studying the effective learning of MOOC, we can evaluate MOOC course scientifically and reasonably. It can bring the correct orientation to MOOC course construction. It also provides learners with more efficient and convenient learning resources.

On the other hand, MOOC's existing knowledge organization model wasted learning a lot of invalid learning time. In order to achieve effective learning, changing MOOC knowledge organization model is imperative. The video needs subdivision based on knowledge points. Establish the classification and hierarchy of knowledge points. Thus, to achieve the learner's on-demand learning goals. Further enhance the learner's dominant position and improve MOOC teaching effectiveness.

\section{REFERENCES}

[1] A. Ogunleye, Quality Assurance and Quality Indicators in Open and Distance Education, International Journal of Educational Research and Technology, 2013, 4(2): $49-62$

[2] O. Darojat, M. Nilson, D. Kaufman, Quality Assurance in Asian Open and Distance Learning: Policies and Implementation, Commonwealth of Learning CC BY SA, 2015.

[3] A. Anderson, D. Huttenlocher, J. Kleinberg, et al. Engaging with massive online courses, 2014:687-698.

[4] P. Adamopoulos, What makes a great MOOC? An interd isciplinary analysis of student retention in online courses. In Proceedings of the 34th International Conference on Information Systems, 2013, ICIS'13.

[5] N. Gillani. Learner communications in massively open online course. OxCHEPS Occasional Paper, 2013:53.

[6] P. J. Guo, J. Kim, R. Rubin. How video production affects student engagement: an empirical study of MOOC videos ACM Conference on Learning @ Scale Conference. ACM, 2014:41-50.

[7] Z. X. Jiang, Y. Zhang, X. M. Li, Learning Behavior Analysis and Prediction Based on MOOC Data, Journal of Computer Research and Development, 2015, 52(3):614-628. (In Chinese)

[8] H. Deng, M. Li, Y. Chi. Courses and knowledge system network modeling in MOOC, Course Education Research, 2013(7),5-7. (In Chinese) 